\title{
AFROLATINOAMERICANAS... UNA EXPERIENCIA DE SUBVERSIÓN ESTEREOTÍPICA EN EL MUSEO DE LA MUJER DE BUENOS AIRES*
}

\section{Lea Geler \\ CONICET/Universidad de Buenos Aires - Argentina}

Resumen: Enestetrabajomecentraréenlaperfomanceteatral Afrolatinoamericanas..., realizada en el Museo de la Mujer de Buenos Aires a finales del año 2010 por un grupo de teatro dedicado a la tematización de la afrodescendencia en la Argentina, un país que hasta hoy día sigue considerándose blanco-europeo y que sostiene que la población de descendientes de esclavizados/as africanos/as ha desaparecido. El análisis de la puesta en escena de dicha obra, en conjunto con el de fuentes históricas, permitirá establecer ciertas relaciones de continuidad entre las situaciones de exposición, objetivación y estereotipación surgidas en Europa y algunos de los lineamientos en que se fueron sustentando las representaciones raciales/sexuales para las mujeres socialmente negras en la Argentina. Haciendo hincapié en la reutilización y crítica producida en la performance de estos elementos propondré repensar a esta intervención artístico-política de autorepresentación como una plataforma privilegiada para su desafio.

Palabras clave: afrodescendencia, Buenos Aires, estereotipos, mujer.

Abstract:In thispaperIwillfocus on the theatricalperformance Afrolatinoamericanas... held in the Women's Museum of Buenos Aires in 2010 by a theater group that focuses on the visibilization of Afro descendants in Argentina, a nation that continues to define itself as white-European and specifies that the population of descendants of enslaved people of African origin have disappeared. The analysis of the staging of

* Una versión anterior de este trabajo fue presentada en el Encuentro Visible/Invisible. Las representaciones de la cultura afro-argentina en los museos, Museo Histórico Nacional y Fundación Typa, noviembre de 2010. Este artículo se inscribe en el proyecto de investigación del MEC, HAR2009-07094, que se desarrolla en el TEIAA (2009SGR1400).

Horizontes Antropológicos, Porto Alegre, ano 18, n. 38, p. 343-372, jul./dez. 2012 
that performance, together with some historical sources, will help me establish continuity relations between exposure situations, objectification and stereotyping emerged in Europe and some of the guidelines that were sustaining the racialized/sexualized representations for black women in Argentina. Emphasizing the critical reutilization of some of these elements, I will propose to rethink this artistic-political intervention of self-representation as a privileged platform for challenging stereotypes.

Keywords: Afro-descendants, Buneos Aires, stereotypes, women.

\section{Introducción}

Si en el imaginario argentino persiste todavía la percepción de ser un país blanco-europeo, debida en parte a la famosa idea de "desaparición" de los descendientes de esclavizados y esclavizadas de origen africano, comienzan a surgir voces, estudios y acciones que permiten poner en discusión pública este supuesto que forma parte del mito de origen nacional. Entre estas últimas se encuentra la performance Afrolatinoamericanas... realizada en el Museo de la Mujer de Buenos Aires en el marco de la "Noche de los Museos"1 del año 2010. El grupo teatral que la creó y puso en escena, dirigido por la directora y actriz afrocubana Alejandra Egido - del que formo parte tanto en carácter de antropóloga-historiadora como de colaboradora general/activista ${ }^{2}$, , se fundó en el año 2010 y hoy lleva el nombre de TES (Teatro en Sepia). ${ }^{3}$ Desde entonces, el trabajo de TES apunta a la tematización de la afrodescendencia en la Argentina, siendo su objetivo principal utilizar el potencial del teatro y del arte para poner en evidencia y cuestionar las construcciones racializadas y racializantes que imperan en un país que se considera no racista (en gran

1 El evento promueve el acercamiento del público a los museos en horarios nocturnos, invitando a una serie de actividades artísticas para acompañar la visita. Fue realizado el 13 de noviembre de 2010.

2 Aunque aquí no problematizaré específicamente este tema, retomo a Kropff (2008) en sus posturas sobre "investigación activista/militante". En este sentido, estaría implicada en la organización "de proyectos de intervención política en conjunto con otros activistas que no necesariamente pertenecen al ámbito académico. Complementariamente, se trata de producir conocimiento académico en función de fortalecer esos proyectos" (Kropff, 2008, p. 32-33). Estas intervenciones políticas se realizan, en este caso, a partir de las prácticas artístico-escénicas, lo que dibuja una concepción de lo político amplia.

3 En el momento de la realización de la performance, parte de lo que hoy es TES se aglutinaba en la Comedia Negra de Buenos Aires.

Horizontes Antropológicos, Porto Alegre, ano 18, n. 38, p. 343-372, jul./dez. 2012 
medida porque se supone que "no hay negros"), y generar movilización política y visibilidad para un colectivo social que fue marcado por su supuesta ausencia. La mayor parte de los integrantes de TES se autoadscriben como afrodescendientes, argentinos/as y latinoamericanos/as, y también participan del grupo no afrodescendientes.

Afrolatinoamericanas..., además de forzar la visibilidad de un grupo "no-existente", puso también en cuestión algunos elementos de la relación entre afrodescendencia y museos, particularmente entre mujeres afrodescendientes y museos. Así, que el espacio de la representación haya sido un museo abrió la puerta a la indagación de las estrechas relaciones entre estas instituciones y las formas de alterización y estereotipación (racial, sexual, etc.) que acompañaron a la modernidad, y su potencial de quebrar construcciones reificadas en la actualidad:

Por un lado, hay que recalcar que el museo moderno deriva de aquellos espacios creados en la Europa del siglo XVII para mostrar colecciones privadas de objetos, clasificados según se los considerara "naturales" o "realizados por el hombre", es decir, según una forma particular e histórica de conceptualización y separación entre naturaleza y cultura. El hilo conductor de estas muestras se encontraba en la caracterización de los objetos expuestos como curiosidades, muchas veces como rarezas en peligro de desaparición (Lidchi, 1997), no casualmente llegadas de territorios que estaban bajo proceso de conquista, colonización o investigación con fines económicos. Este movimiento conllevaba en sí mismo la definición de lo "propio", asumido como normal, y de lo "otro" o alteridad, evidentemente rara, no-normal (con sus ideas concomitantes de desviación, patología, etc.). A lo largo del siglo XIX, los museos se constituyeron como un escaparate privilegiado para que los Estados mostraran y organizaran visualmente sus formas y proyectos de nación, utilizando la gran capacidad de generar o moldear subjetividades que poseen estos espacios que pasaron a formar parte de la red de instituciones generadoras de "archivo", es decir, pensadas para cobijar la selección de objetos o hechos destinados a rescatar, hacer perdurar y/o conformar aquello designado como significativo y recordable de una formación nacional (Trouillot, 1995). Aun hoy, construir una exhibición museística es un proceso de desestimación y aprobación de ciertos objetos, dándoles sentido como guión (poniéndolos en relación entre sí según determinados objetivos o ideas), así como de autorización de la voz del guionista y sus concepciones. Teniendo esto en 
cuenta, y siguiendo a pensadoras foucaultianas como Preciado (2008), pueden entenderse a los museos como una de las tecnologías biopolíticas de producción y legitimación de diferencia más potentes, que cuenta con sus propios dispositivos de visibilización y exposición, agudizados en la actualidad por la masificación de los procesos de espectacularización del cotidiano. Debord (1995) puntualiza que el proceso espectacular necesita de la coagulación de la actividad humana, es decir, seleccionar, separar, reordenar, catalogar lo que previamente se encuentra en un estado fluido, para permitir-mediante la exhibición- su visualización, interpretación y posesión; su producción y reproducción ya como mercancía, con su contraparte de fetichización. Los museos etnográficos, por ejemplo, nos instalan rápidamente ante "el otro cultural", haciéndonos partícipes como espectadores del proceso de su "objetivación" y de interpretación del mundo como totalidad cognoscible desde un "nosotros" que se va conformando y asumiendo en esa relación. Esta idea de la exhibición museística de lo "otro" como forma de conocimiento fue llevada a sus últimas consecuencias en el siglo XIX y principios del XX, cuando los museos -tanto etnográficos como de ciencias naturales-acogían la exhibición continuada de seres humanos/"objetos" realizando actividades propias de sus "otras" culturas, o de sus cuerpos indicativos de "desviaciones" o "atrasos" biológico-raciales-morales, produciendo y sosteniendo representaciones sociales, raciales y sexuales cuya continuidad en la actualidad es sorprendente (Hall, 1997). Este fue uno de los puntos retomado por el grupo teatral para construir la performance.

Por el otro, vale aclarar que el Museo de la Mujer no es un museo más de arte o de historia sino que es un espacio ligado a la lucha feminista, que acoge el arte y la historia desde un descentramiento de las categorías hegemónicas basadas en el par sexo/género. Los museos de la mujer -de los que hay 50 alrededor del mundo conectados por la red "womeninmuseum"- trabajan para apoyar el arte hecho por mujeres, contar la historia de las mujeres en cada país y asistir en proyectos de investigación; ganando visibilidad para la mujer, su trabajo y las desigualdades en las que se ve inmersa. ${ }^{4} \mathrm{Al}$ abrir un espacio para la mujer y, además, para la mujer afrodescendiente, el Museo de la Mujer de Buenos Aires ofrecía la posibilidad de problematizar las variadas formas en

4 http://www.womeninmuseum.net/blog/?page_id=2 (enero de 2012).

Horizontes Antropológicos, Porto Alegre, ano 18, n. 38, p. 343-372, jul./dez. 2012 
que las mujeres afrodescendientes en el país -socialmente negras ${ }^{5}$ o no- fueron y son estigmatizadas, marginalizadas, invisibilizadas y/o discriminadas, en estereotipaciones que son globales al mundo capitalista y, sobre todo, que los mismos museos ayudaron a consolidar. Por lo demás, la invitación del Museo de la Mujer respondió asimismo a que Alejandra Egido es activista feminista.

De esta manera, la realización de la performance, que llevó más de tres meses de elaboración y ensayos, presentó una condensación de sentidos, posibilidades e interrogantes interesantes tanto para la discusión teórica como para la acción política.

Desde la antropología y la antropología histórica, a partir de mi trabajo de campo como parte de la compañía teatral y también del análisis de fuentes históricas/literarias, en este artículo propondré hacer un contrapunto entre lo que sucedía en el siglo XIX y principios del XX y la actualidad. El objetivo será exponer el enraizamiento, continuidad y fortaleza de ciertos sentidos racializados y sexualizados con los que se perpetúa y reproduce el estereotipo de la mujer socialmente negra en la Argentina, y analizar la performance teatral como un proceso de subversión del mismo. Así, teniendo en cuenta que "la manera como las cosas son representadas y [que] las «maquinarias» y regímenes de representación en una cultura juegan un rol constitutivo, y no únicamente un rol reflexivo con posterioridad al hecho" (Hall, 2010, p. 307, énfasis del autor), buscaré, en primer lugar, establecer ciertas relaciones entre las situaciones de exposición, objetivación y estereotipación surgidas en Europa y algunos de los lineamientos en que se fueron sustentando las representaciones raciales/sexuales para las mujeres socialmente negras en la Argentina. En segundo lugar, analizaré la performance realizada en el Museo de la Mujer de Buenos Aires por el grupo teatral, haciendo hincapié en la reutilización y subversión producida de algunos de estos elementos, proponiendo repensar a las intervenciones artísticas de autorepresentación como plataformas privilegiadas para su desafío, cuyo potencial político aun permanece mayormente inexplotado dentro del ámbito de las artes visuales en el país.

5 Retomo la categorización de las personas como "socialmente negros/as" de Ferreira (2008), para hacer hincapié en los modos socialmente construidos, históricos y cambiantes en que se perciben los colores de la piel. 


\section{Venus locales y extranjeras, del pasado y del presente}

Al tratarse del año del Bicentenario de la Revolución de Mayo (1810), uno de los ejes en que se había basado la invitación del Museo de la Mujer al grupo de teatro era la reivindicación de la participación de la mujer afrodescendiente en la historia argentina. Aunque este pedido se tuvo en cuenta, no quisimos dejar de lado las particularidades que la propuesta abría, iniciándose un proceso de búsqueda de la relación entre las mujeres afrodescendientes y los museos. Por ello, llevé el caso de Sara Baartman a la discusión grupal que se convirtió, con el transcurrir de los ensayos, en uno de los impulsores desde el que pensar y organizar la propuesta general. Como veremos, aquella situación histórica que aparenta ser de total exterioridad a la realidad argentina está estrechamente relacionada con la construcción del archivo representacional de la mujer socialmente negra en Buenos Aires.

Sara Baartman (1789-1815), una mujer khoikhoi (Sudáfrica) tristemente conocida como Venus Hotentote, representa uno de los casos más paradigmáticos y de mayor repercusión de exposición de seres humanos. Esclavizada y llevada a Inglaterra en 1810 (otro Bicentenario...) por un empresario boer, Baartman fue regularmente exhibida durante cinco años en ciudades como Londres o París (Qureshi, 2004). Sus primeras presentaciones estaban muy ligadas a la imagen de un animal salvaje en una jaula, y se la mostraba respondiendo a las órdenes de un eventual "cuidador" (Hall, 1997). El impacto de la exhibición de Baartman en las sociedades inglesa y francesa fue tan alto que su imagen comenzó a recorrer incesantemente los medios científicos, artísticos y de comunicación, que se afanaban en reproducir y estudiar su figura. ${ }^{6}$

Desde la óptica europea de la época, la esteatopigia de Sara Baartman, sus labios genitales agrandados, grandes pechos y muy corta estatura, sin olvidar que era socialmente negra y que provenía de un pueblo africano (es decir, "primitivo"), eran un conjunto extraordinario de "rarezas" que llamaban la atención del público y que llevó a que naturalistas y etnólogos midieran, observaran, modelaran y revisaran cada centímetro de su cuerpo. Esto se agudizó una vez Sara Baartman murió de viruela en París. Allí, sus restos fueron

6 También generó gran controversia, especialmente entre los abolicionistas que llevaron a juicio estas presentaciones. Sin embargo, se permitió continuar con ellas (Qureshi, 2004). 
diseccionados por Georges Cuvier -zoólogo francés cuyas investigaciones contribuyeron a la formación de la teoría racial científica- y expuestos nuevamente, ahondando en el espectáculo de lo anormal y lo patológico, lo natural y lo primitivo. En nombre de la ciencia se la inmortalizó como un espécimen biológico y hasta los años 70 del siglo $\mathrm{XX}$ su esqueleto fue exhibido en el Musée de l'Homme de París (Qureshi, 2004). Luego, sus restos se guardaron hasta que se confirmó su repatriación a Sudáfrica -que la pedía desde 1995en abril de 2002.

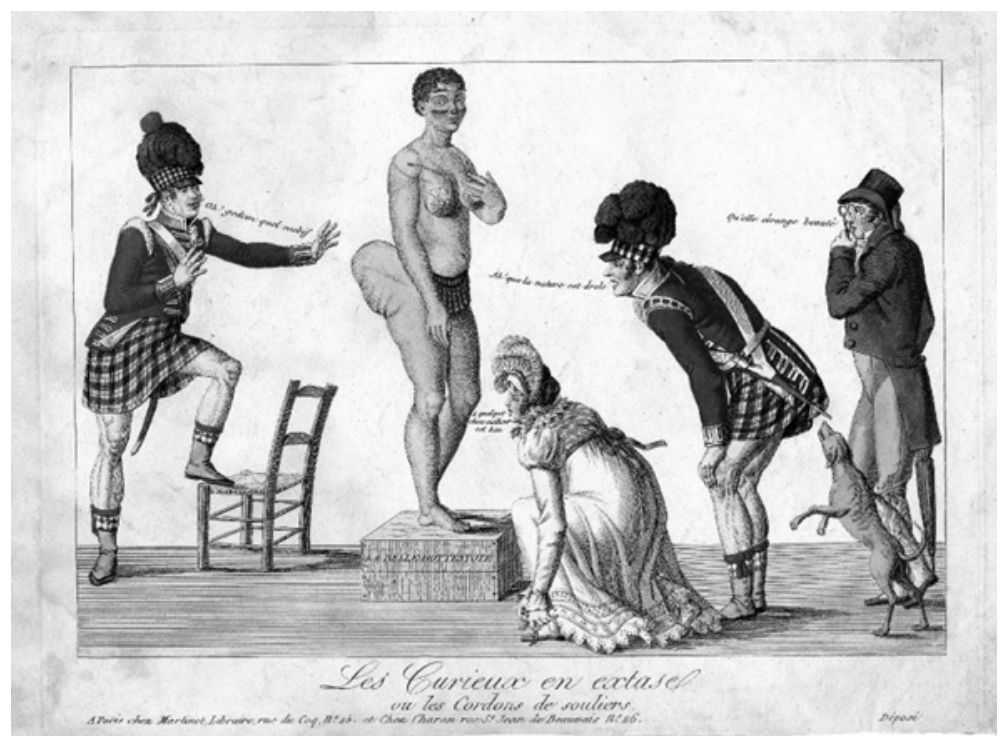

Figura 1. "Los curiosos en éxtasis" (Les Curieux en extase ou les Cordons de souliers, 1814) http://marinni.livejournal.com/551958.html (octubre de 2010).

La exhibición de Baartman, además de un proceso de reificación y legitimación de la normalidad/anormalidad, validaba la visualidad como metodología de conocimiento y aprehensión del "otro", objetivándolo. Era, también, un eslabón más, e imprescindible, de dotación de materialidad al estereotipo de la mujer socialmente negra continuamente en construcción y circulación. Este estereotipo lleva implícitas las ideas de sexualidad "salvaje", fortaleza 
física y agresividad, unificando a todas las mujeres socialmente negras como un objeto de deseo y de burla, dominación, miedo y poder (Bhabha, 2002), habilitando la esclavización, abuso y carga de trabajo teóricamente no aplicable a las "mujeres" (blancas) por su supuesta debilidad innata (Lugones, 2008).

La influencia de este tipo de imagen fue tan grande que la creación en Inglaterra, a mediados del siglo XIX, del miriñaque victoriano se puede relacionar directamente con la figura estereotípica que representaba Baartman de la mujer socialmente negra/hipersexual, y con el ansia de estimular la imaginación de los hombres blancos burgueses de la sociedad europea, dejando al descubierto la gran carga de deseo que contenía (Hall, 2010). De este modo, las mujeres blancas burguesas pasaron a "imitar" -o fueron compelidas a imitar- la parte trasera del cuerpo de Baartman en vestidos que remedaban su esteatopigia. $^{7}$
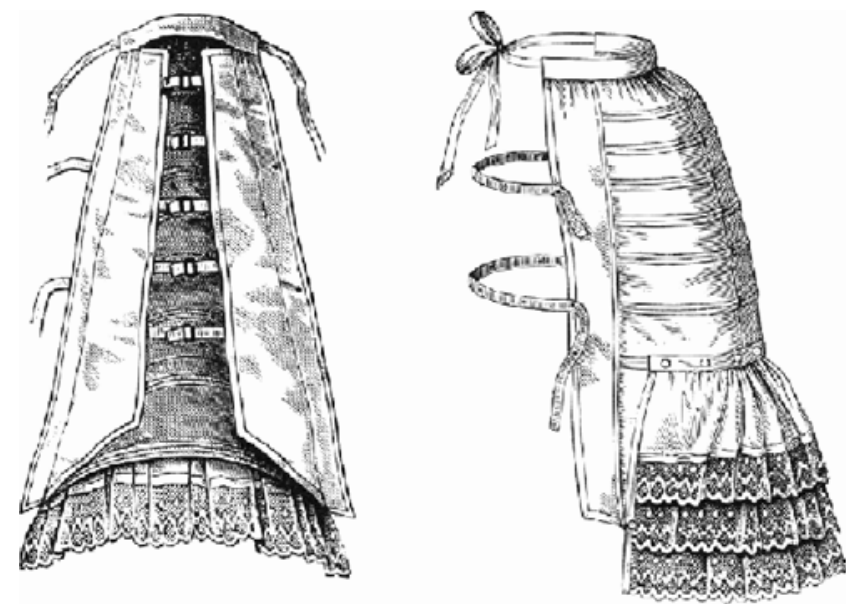

Figura 2. Esquema miriñaque victoriano (1881) - http://en. wikipedia.org/ wiki/Bustle (septiembre de 2010).

Debemos recordar que estos aparatos relativos al vestido femenino, de una visualidad y funcionalidad muy ligada a elementos médicos y quirúrgicos, lograban efectivamente que la mujer fuera corporalmente más débil. Es decir, si no se puede respirar, el cuerpo se debilita; al igual que si no se puede andar, correr, etc. (Connerton, 1989). 


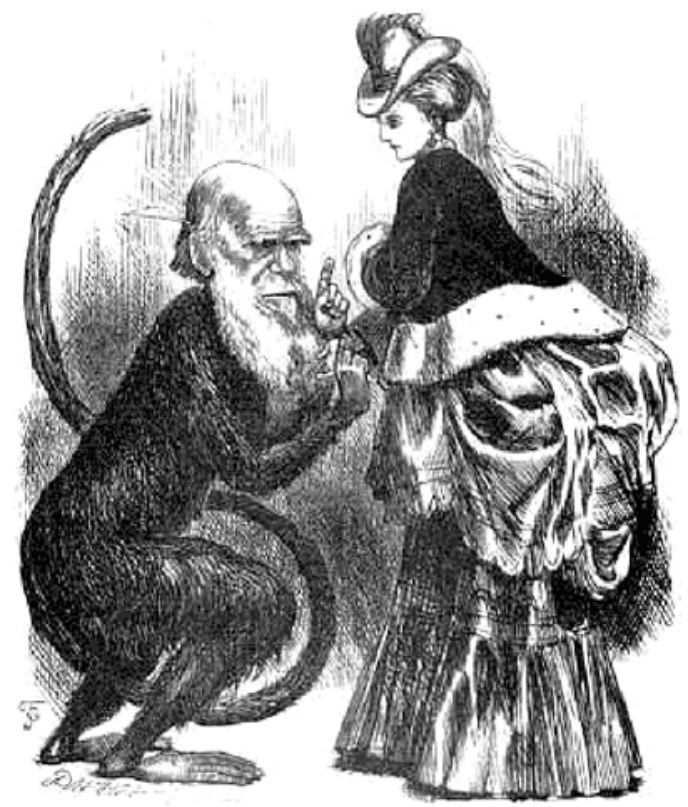

Figura 3. Caricatura de Darwin y la "selección sexual". Publicada en la revista fun (1872) http://en. wikipedia.org/wiki/Sexual_selection (septiembre de 2010).

Detengámonos un momento en la caricatura reproducida en la figura 3. En ella se enfatizaba, gracias a la esteatopigia impuesta por el miriñaque victoriano, la atracción que supuestamente sentía Darwin hacia la mujer que llevaba este aparato. Y si bien es cierto que dibujar a Darwin como un mono estaba relacionado con su Teoría de la Evolución (su libro El origen de las especies se había publicado en 1857), no debemos perder de vista que los hombres y mujeres socialmente negros/as eran ubicados más cerca de estos animales que de los humanos en una supuesta línea evolutiva que implicaba el mejoramiento progresivo de la especie. Así, la caricatura jugaba con el doble sentido racial/sexual: mostraba a un mono (un negro) que no podía controlar sus instintos sexuales (hombres y mujeres socialmente negros/as son considerados/as agresivos/as sexualmente) frente a una esteatopigia, que sería algo particular de las mujeres socialmente negras y cuyo erotismo se buscaba para las mujeres socialmente blancas. 
Por supuesto, la Argentina no era ajena a ninguno de estos procesos históricos. Por un lado, se producían en el país desde fines del siglo XIX exposiciones en los museos locales donde se exhibían restos de personas, en este caso indígenas (Rodríguez, 2010). Por el otro, se asentaba la ausencia de representación afro de los museos. Esta falta completa de representación afroargentina -en tanto tal- de los museos, es decir, la falta de archivo, debe ponerse en relación con el tipo de discurso e imagen de nación (blanca-europea) que se estaban intentando proyectar y con la formación nacional de alteridad que se construía (Briones, 2005), y es análoga al borramiento de lo afro de la historia nacional posterior a 1850. En este sentido, los afrodescendientes argentinos no fueron marcados como alteridad interna sino que sufrieron la homogeneización forzosa a la blanquitud que proponía el Estado (Geler, 2010) o, en su defecto, negación, extranjerización y marginación (Frigerio, 2006). ${ }^{8}$ No hay que olvidar que buena parte del poder de las representaciones visuales sostenidas desde instituciones museísticas reside en la capacidad de generar reconocimiento por parte del espectador. Es decir, para un/a connacional argentino/a "verse" en un museo nacional implica también verse como blanco/a-europeo/a, porque este es el postulado de la normalidad de esta nación. Así, la decisión de erosionar la imagen de lo percibido como negro/a de los museos responde también a la imposición de blanquitud y a la necesidad de no generar "dudas" con respecto al propio "color" en un/a espectador/a sujeto/a a un proceso profundo de creación de subjetividad en su diálogo con las instituciones estatales-nacionales.

Sin embargo, y aunque la ausencia de la mujer socialmente negra de los museos fue uno de los leitmotiv de la performance Afrolatinoamericanas..., es necesario rastrear las imágenes de las mujeres socialmente negras reelaboradas a partir de los planteamientos surgidos en Europa que excedían el ámbito museístico pero que se inveteraban en el imaginario social a través de su importancia en la esfera pública, dotándolos de gran materialidad y potencia. Para nuestro caso particular, propongo recorrer algunas de éstas, elaboradas

\footnotetext{
8 La extranjerización del hombre y la mujer percibidos/as socialmente como negros/as es un hecho que deben enfrentar cotidianamente los afrodescendientes y las afrodescendientes argentinos/as socialmente negros/as, posibilitando la ocurrencia de casos extremos como el vivido por María Magdalena Lamadrid en el Aeropuerto Internacional de Ezeiza (Buenos Aires) en el año 2002. La Sra. Lamadrid fue detenida por la policía de migraciones que alegó que su pasaporte argentino era falso. Ella no podía ser argentina ya que es socialmente negra. La noticia salió publicada en el diario Clarín del 24 de agosto de 2002.
}

Horizontes Antropológicos, Porto Alegre, ano 18, n. 38, p. 343-372, jul./dez. 2012 
por reconocidos miembros de las elites políticas, económicas o intelectuales del país, ya sea a partir de dibujos o de palabras, para rastrear las sorprendentes continuidades a través del tiempo de ciertos diacríticos, que fueron y van marcando y formando la imaginación estereotípica sobre la mujer afrodescendiente en Buenos Aires.

En 1869, por ejemplo, la comparsa carnavalesca de la clase social porteña más alta se autodenominaba "Los Negros" y sus participantes salían a la calle a desfilar con la cara tiznada, recreando danzas que aludían a los candombes, continuamente sexualizados y representados como parte del grotesco-popular por sus relatores. Aunque aquí no indagaremos en esta comparsa ${ }^{9}$-que nos introduce de lleno en el juego entre "ser" y "representar" y las relaciones de dominación cimentadas sobre la producción de sujetos estereotipados-, ciertamente hay que destacar que no es casualidad que fuera en su periódico donde se publicó la siguiente viñeta:

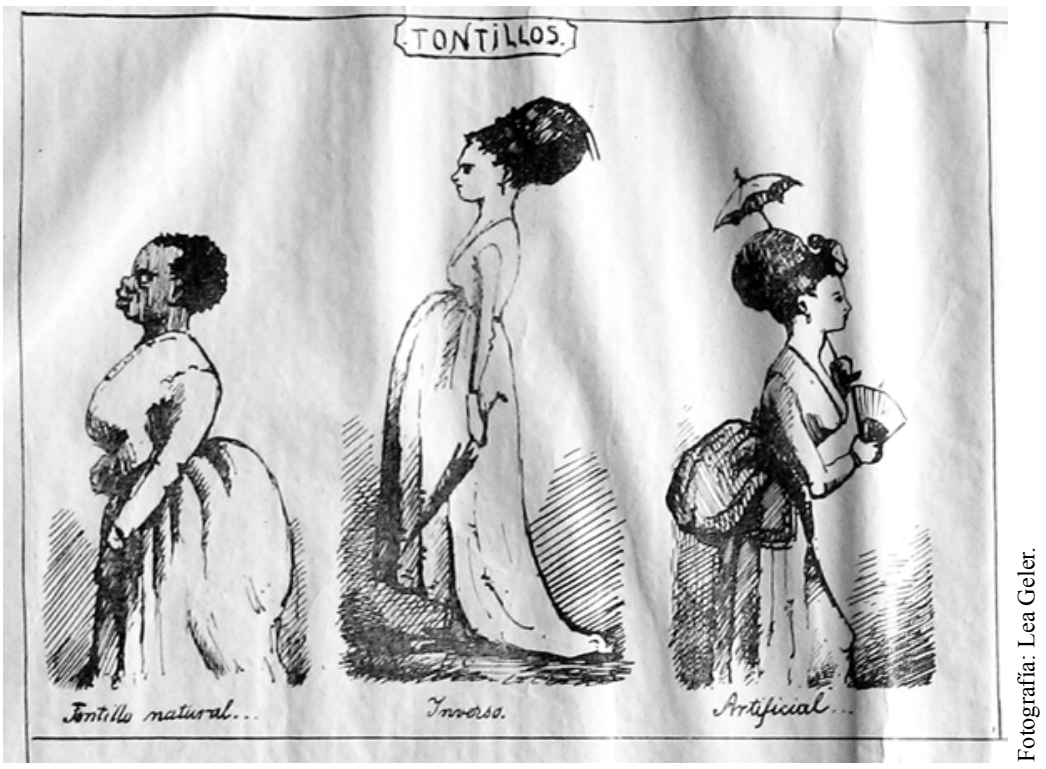

Figura 4. Periódico Los Negros, 14 de noviembre de 1869.

\footnotetext{
9 Sobre la comparsa Los Negros y la creación del "personaje del negro", ver Geler (2011a, 2011b).
} 
Esta caricatura -que aludía a la utilización del miriñaque victoriano, llamado "tontillo" en referencia al miriñaque estilo español- muestra cómo los lineamientos generales sobre la representación de la mujer socialmente negra sedimentados a partir de la exposición de Sara Baartman llegaban a Buenos Aires, y eran retomados por las elites locales, tal vez incluso sin el conocimiento de su origen. En esta viñeta se implicaba que las mujeres socialmente blancas sólo podrían representar la forma corporal de una mujer socialmente negra, mientras que las mujeres socialmente negras "de verdad" la ostentarían por naturaleza, y de hecho no la podrían ocultar (Fanon, 1973). Esta "naturaleza" siempre expuesta puede ser reapropiada por las mujeres socialmente blancas, aunque la situación nunca puede ser inversa. La imagen indica, además, la diferencia de clase establecida entre la mujer socialmente blanca y la mujer socialmente negra (mostrando peinados y accesorios diferenciales), la autoridad de la mujer blanca que vuelve moda algo de otra forma impensable, la apropiación de los atributos del "otro" y los requerimientos de los hombres sobre todas las mujeres (blancas y negras) como cuerpos eróticamente interesantes/accesibles.

$\mathrm{Y}$ al igual que la figura de Darwin se usaba en Inglaterra para connotar la poca evolución y salvajismo de las personas socialmente negras, en Argentina se publicaba, en uno de los números de la exitosa revista Caras y Caretas de 1903, una especie de árbol filogenético "linneano" donde quedaba patente no sólo la posición de hombres y mujeres socialmente negros/as sino también que era el varón blanco y burgués (clase social evocada por el bigote, peinado y anteojos) quien se encontraba en la cúspide de la pirámide evolutiva por sobre la mujer blanca/burguesa y las mujeres en general, dejando en evidencia no sólo el tratamiento de semi-animalidad a los hombres y mujeres socialmente negros/as sino también algunas de las múltiples formas de dominación a que las mujeres socialmente negras se ven sometidas.

En la misma línea pero dentro del ámbito de la literatura, los escritores antirosistas destacaban la "animalidad" de las mujeres socialmente negras. Es conocido El matadero de Esteban Echeverría (1874, p. 224), escrito en 1838, donde mostraba a las mujeres negras de un modo bestial, recogiendo desechos de carne de los alrededores de un matadero, incluso peleando con (y como) los perros: "[...] negras y mulatas achuradoras, cuya fealdad trasuntaba las arpías de la fábula, y entremezclados con ellas algunos enormes mastines, olfateaban, gruñían o se daban de tarascones por la presa". 


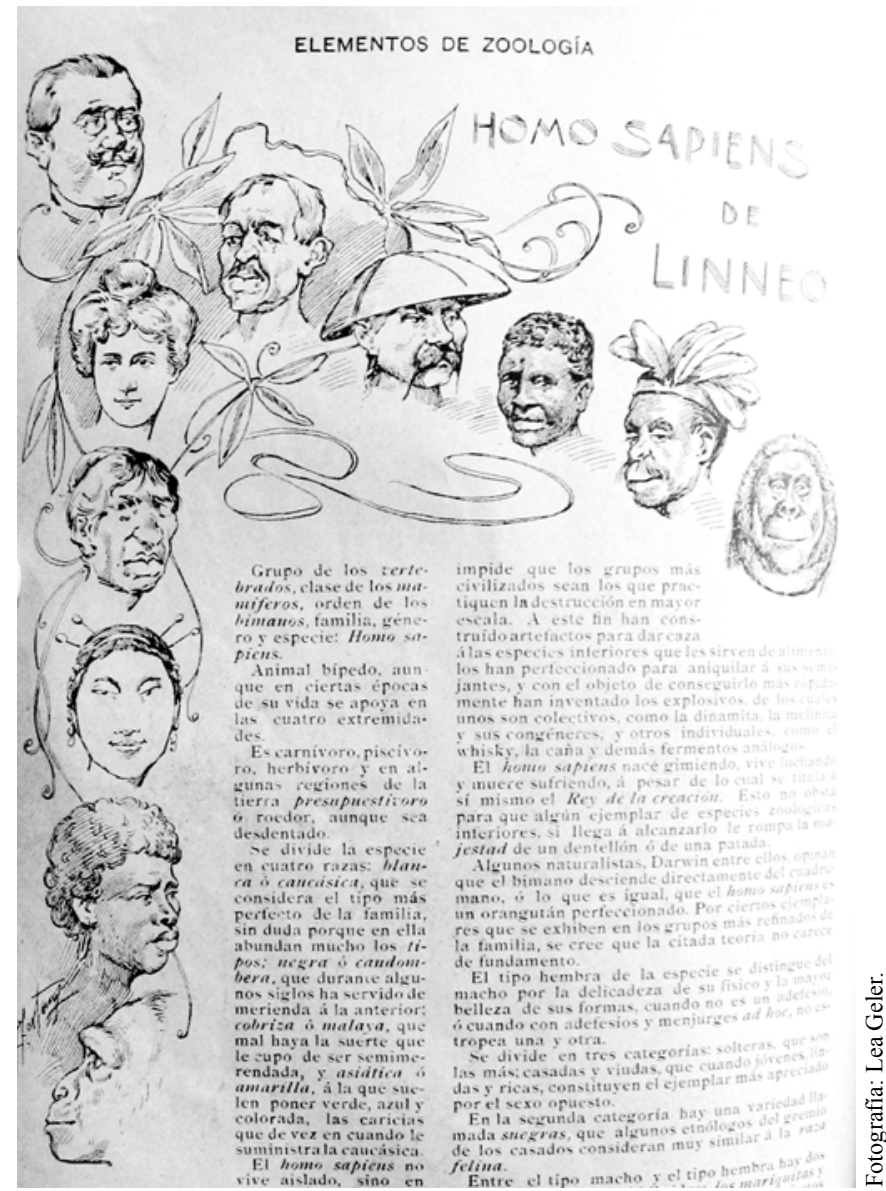

Figura 5. Caras y Caretas, 20 de junio de 1903.

La Amalia de José Mármol de 1851, por poner otro ejemplo de los considerados "padres" de la literatura nacional, exponía a las negras y mulatas siempre en actitudes grotescas, y desagradables, comparables desde todo punto de vista, con los animales: "La [bella] joven pisó el umbral de aquella puerta y tuvo que recurrir a toda la fuerza de su espíritu, y a su pañuelo perfumado, para abrirse camino por entre una multitud de negras, de mulatas, de chinas, de patos, de gallinas, de cuanto animal ha criado Dios..." (Mármol, 1872, p. 88). 
Asimismo, algunos escritores enfatizaban en la contraparte de erotismo y sexualidad que componía el mismo estereotipo. Uno de ellos fue José Ramos Mejía quien, en 1907 (aunque supuestamente recordando el suceso de su infancia), describía a las mujeres socialmente negras en un desfile de carnaval por las calles de Buenos Aires:

[...] marchaban [...] imprimiendo al cuerpo movimientos de una lascivia solemne y grotesca. Las negras, muchas de ellas jóvenes y esbeltas, luciendo las desnudeces de sus carnes bien nutridas, revelaban en sus rostros alegres, un ánimo satisfecho y despreocupado. Las gráciles Venus imponían con indolencia las mamas rotundas como una expresión de su poder fecundante. (Ramos Mejía, 1907, p. 330).

Nuevamente, no se puede dejar de notar la gran carga de fantasía y deseo que se revelan en las palabras del autor sobre las mujeres socialmente negras, que, tal como le había sucedido a Sara Baartman, eran denominadas como "venus". Las "carnes nutridas" o las "mamas rotundas" componen una figura que se acerca a la imagen que Baartman habría materializado, y aquí se agrega la aparente "satisfacción" y "alegría" de estas mujeres. Aquella supuesta genuina satisfacción y desinhibición sexual habilitaba moralmente a los hombres para abusar repetidamente de las mujeres socialmente negras, esclavizadas o no.

Estos modos de representación de la mujer socialmente negra no están ausentes del país hoy día. De hecho, la imagen de la mujer socialmente negra que recorre el sentido común nacional está relacionada con una figura caricaturesca denominada la "mulatona", del dibujante Caloi (Carlos Loiseau), perteneciente a la tira cómica Clemente nacida en 1973. Este personaje, que desde su mismo nombre alude a una "mezcla" y, a pesar de ello, respondiendo a las categorías clasificatorias locales ${ }^{10}$ es leído de forma que se lo posiciona en un extremo de la perceptibilidad social de negritud, no escapa a la extranjerización que sufren todos/as los/as afrodescendientes en la Argentina, siendo que la mulatona es brasilera. Sugestivamente, la mulatona -que no tiene nombre propio- muestra una figura muy similar a la de Sara Baartman,

10 Sobre el tema de las categorías clasificatorias en Buenos Aires, ver Frigerio (2006, 2009) y Andrews (1989). 
con atributos sexualizados superdesarrollados, designando su supuesta hipersexualidad y erotismo. Por ello, no sorprende que la mulatona sea el objeto de deseo de Clemente, el protagonista de la tira.
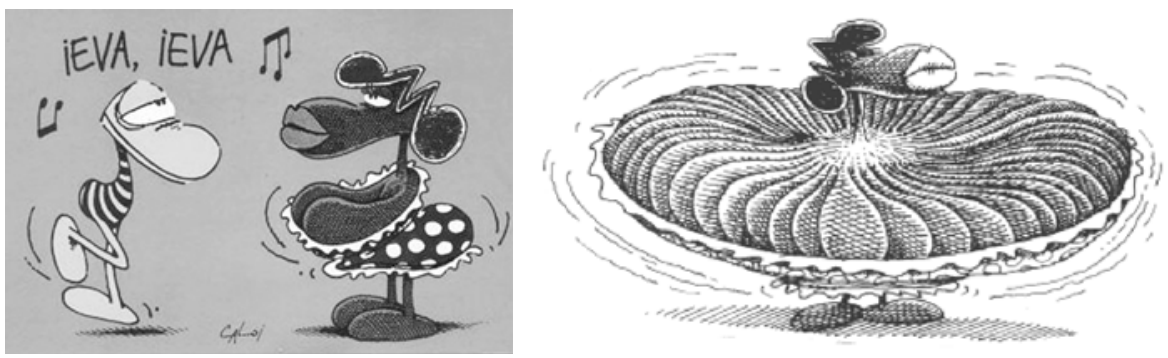

Figuras 6 y 7. La mulatona de Caloi - Google Images.

La figura de la mulatona es tan importante que se ha convertido en la representación de todas las mujeres socialmente negras en el país. Es decir, extranjera y con una hipersexualidad a "flor de piel". Pero, como resaltan Hall (1997) o Bhabha (2002), las construcciones estereotípicas refieren tanto a lo percibido como a lo imaginado o deseado que conllevan, produciendo imágenes que hablan por lo que dicen pero también por lo que permiten fantasear, lo que queda implícito. Así, por más que en una mujer socialmente negra no se perciban los rasgos pre-asignados a su "raza", la imagen que se leerá de ella no prescindirá de los mismos, haciéndosele inevitable. Por eso, aun hoy en una Argentina que no se considera racista, las mujeres socialmente negras no pueden evitar que recaiga sobre ellas una mirada "cargada" que, además de extranjerizarlas y negarles su historia, las lleva a sentirse (como sucede en gran parte del mundo) siempre interpeladas y en general "obligadas" a tener que demostrar su recato, educación, buenos modales, etc. frente a una mujer blanca burguesa que es la imagen genérica con que se construye a la mujer y que, por lo mismo, no tiene nada que demostrar, por lo menos en relación con esos puntos (Lugones, 2008).

En este contexto, la propuesta del Museo de la Mujer de Buenos Aires se presentó como una oportunidad ideal para comenzar a perturbar o a poner en cuestión algunos de los elementos discutidos hasta aquí. 


\section{La Noche de los Museos, una propuesta de autorepresentación}

Ni bien surgió la posibilidad de realizar la performance en el Museo de la Mujer se plantearon en el seno del grupo tres puntos desde los que pensar la puesta: a) el museo como reflejo de la nación (no hay negros/as); b) el museo como maquinaria otrificadora (lo negro como alteridad) y c) el museo como ausencia de lo (afro)femenino (patriarcado/racializador). Estos puntos fueron complejizándose, haciendo de la presentación un evento que generó una cantidad enorme de tensiones y posibilidades.

Una de estas tensiones radicó en que, al dedicar la noche a la mujer afrodescendiente, la institución volvía a la paradoja de reificar la diferencia y lo "normal", ofreciendo un espectáculo que se presentaba como sumatoria de distinciones (mujer/afrodescendiente) aun dentro de la diferencia (mujer), que podría llevar nuevamente a la consolidación de una visión de otredad. Asimismo, como vimos, el ámbito museístico opera sobre objetos/sujetos previamente seleccionados según sus cualidades de vulnerabilidad/visualidad que devuelven colecciones y archivos. De este modo, el espectáculo también podría ahondar en el sentido común del criterio de "recordar" y hacer archivo, ver para guardar en la memoria una parte del pasado considerado desaparecido, escaso o vulnerable, un sentido que se ahondaba con el requerimiento por parte del museo de poner en escena la temática de la mujer afrodescendiente en la historia. Del valor político inherente a la revisibilización se pasaría, entonces, a la reafirmación de la idea de desaparición afrodescendiente en el país, de pasado y no de presencia. Esto último quedó patente cuando el museo propuso para titular la noche: "Mujeres afrodescendientes: 200 años de historia". En respuesta, pedimos el cambio de la palabra "historia" por el de "presencia", y la muestra pasó a llamarse: "Mujeres afrodescendientes y su presencia en más de 200 años de historia". Por último, se tuvo muy en cuenta que el museo es una institución que tiene una historia particular de exhibición de personas y al hacerlo éstas quedan transformadas en objetos, siendo en este punto la relación particularmente problemática para el caso de las mujeres afrodescendientes y los estereotipos construidos sobre ellas como objetos sexuales.

A pesar de todo esto, entendimos que se podían hacer frente a estas paradojas y reutilizarlas a partir de la complejización del subtexto de la puesta y convirtiendo al espacio museístico en un lugar desde donde interpelar el archivo representacional tanto del museo como del público. Al decir de Preciado 
(2008), no se trata de abolir el museo sino de reapropiarse de las estrategias de visibilidad que éste genera desde las minorías y grupos subordinados. El arte, en este sentido, puede ser el lugar desde el que repensar los criterios de diferencia o de normalidad, y ponerlos en jaque.

El espectáculo de la Noche de los Museos, Afrolatinoamericanas. De voces, susurros, gritos y silencios, se realizó en el hall central del Museo de la Mujer y recorrió seis textos, una canción y un tango, de los siglos XIX, XX y XXI, en su mayoría escritos por mujeres afrolatinoamericanas: la carta de 1821 de la soldado esclavizada Josefa Tenorio pidiendo su libertad, ${ }^{11}$ la recreación de un juicio de divorcio ocurrido en la ciudad de Córdoba entre 1805 y 1841 donde mujeres esclavizadas y libres daban testimonio de sus vidas, ${ }^{12}$ una narración que la afroporteña Felisa Pasos publicó en 1878 en el periódico afroporteño $L a$ Juventud $;{ }^{13}$ dos poemas de la escritora y antropóloga afrocostarricense Shirley Campbell Barr, ${ }^{14}$ un poema de la poeta afrocubana Georgina Herrera, ${ }^{15}$ una canción utilizada por las hermanas afroargentinas Carmen y Susana Platero para su obra Calunga Andumba: el "Candombe de la Negrada" y, por último, el conocido tango "El Choclo" del europorteño Enrique Santos Discepolo.

La elección de estas piezas en particular respondió a la idea de hacer decir y hacer escuchar las palabras y los silencios de estas mujeres. Algunas aludían directamente a una situación de "resistencia" -que sería lo esperable de una puesta teatral de este corte- mientras que otras simplemente dialogaban con los contextos en que estas mujeres debían habitar, con sus ideologías específicas -el patriarcado, la esclavitud, el abuso sexual, la lealtad, la amistad, la memoria, el olvido, etc.- mostrándolas con las incertidumbres y luchas que debían afrontar para confrontarlas con nuestro tiempo y nuestra mirada. Eludir explícitamente la homogeneidad textual de la resistencia apuntó a desmarcarse

${ }^{11}$ La carta estaba dirigida a San Martín, Monteagudo y Guido (Taullard, 1927).

${ }^{12}$ En él la querellante, Dña. María Antonia Mercado, lleva de testigos a las esclavizadas del matrimonio y a otras mujeres afrodescendientes sujetas a la violencia de su esposo: Mercedes, Juliana, Bernarda y Ascensión Díaz. Expediente trabajado en Guzmán (2009).

${ }^{13}$ El escrito titulado "Una ilusión" invita a reflexionar sobre el sistema patriarcal que se estaba imponiendo sobre las mujeres en Argentina, y que pesaba doblemente en el ámbito de las mujeres afroporteñas. Texto trabajado en Geler (2007).

14 "Porque me da la gana" y "Se nace mujer", reproducidos en: http://rotundamentenegra.blogspot.com/ (noviembre de 2010)

15 "Elogio para las negras viejas de antes", reproducido en: http://www.terra.es/personal9/maritza2099/ papeles/elogio.html (diciembre de 2010).

Horizontes Antropológicos, Porto Alegre, ano 18, n. 38, p. 343-372, jul./dez. 2012 
del discurso anti-racista que "ha comúnmente utilizado una estrategia de reversos y de inversión, volteando la «estética maniquea» del discursivo colonial de arriba abajo" (Hall, 2010, p. 309) y tenía la intención de generar en el espectador la reflexión acerca de las múltiples facetas de la dominación de género/sexual y racial, y las múltiples formas de hacerle frente. Creo que la posibilidad de realizar este desplazamiento respondió, en gran medida, a que éste fue un proceso artístico-político de autorepresentación -tanto por el origen de los textos como porque las actrices y la directora se autoadscriben como afrodescendientes-, no casualmente habilitado por un espacio como el Museo de la Mujer, que está enfocado a la generación de representaciones alternativas al orden patriarcal y la heterosexualidad normativa.

Porque hay que destacar que las autorepresentaciones de grupos subalternizados no llegan o suelen ser truncadas en las esferas públicas burguesas por los grupos hegemónicos (Fraser, 1997). En este sentido, en un trabajo anterior (Geler, 2010) estudié extensamente la producción periodística de la comunidad afroporteña de fines del siglo XIX, momento de consolidación del Estado argentino, de la idea de desaparición de los "negros" y de la construcción de la nación "blanca-europea". Y si el Estado actuaba impidiendo la visibilidad grupal "de color" ${ }^{16}$ pero habilitando la integración en un pueblo racializado al blanco, el fuerte intento de autorepresentación que significaron los periódicos afroporteños fue ignorado sistemáticamente por la burguesía porteña, generando no sólo la queja de los implicados sino también gran conflictividad en la misma comunidad. Las mujeres, por su parte, veían seriamente -aunque no completamente- condicionada sus posibilidades de autorepresentación en los periódicos comunitarios debido a la imposición de la ideología de domesticidad entre los afroporteños (Geler, 2007), dejando en evidencia el proceso de sedimentación de relaciones de poder y desigualdades diferenciales entre hombres y mujeres socialmente negros/as, siendo estas últimas protagonistas de una posición de desventaja compleja de asir desde una perspectiva lineal.

Igualmente, las artes escénicas han coartado una y otra vez la participación de actores y/o actrices socialmente negros/as en los escenarios. Es que, retomando aquella tradición que había inaugurado la comparsa de elite Los

16 Por ejemplo, cuando prohibió la realización de una manifestación por las calles del centro de la ciudad de la "sociedad de color", en el año 1880 (ver Geler, 2006, 2010). 
Negros (en cuyo periódico se publicó la viñeta reproducida anteriormente), el personaje del "negro" o de la "parda" en las tablas porteñas -de importancia a fines del siglo XIX y hasta las primeras décadas del siglo XX en el teatro popular- eran en general representados/as por actores/actrices socialmente blancos/as que salían a escena tiznados/as. ${ }^{17}$ Con el correr de las décadas, el personaje del "negro" o de la "negra" quedaría reducido al de esclavo/a o sirviente/a, y con suerte al de bailarín/a, es decir, llamarían a los actores y actrices afrodescendientes socialmente negros solamente cuando hubiera un papel para "hacer de negro". Durante el siglo XX, se intensificó esta discriminación, siendo el relato de Rita Montero - actriz afrodescendiente socialmente negra- en la década de 1940 a la revista ;Aqui está! uno de los más elocuentes para describir la tristeza generada por la infalible respuesta en los castings: "negros no" (Patti, 1946, p. 8). Del mismo modo, el suicidio, a comienzos de la década de 1990, de la actriz afroargentina Virginia Murature, cansada de esperar poder representar un papel que no fuera de "negra" (Corrêa, 2006), muestra con crudeza las dificultades de acceder a cualquier tipo de representación que no sean las establecidas por los lineamientos racializados estereotipados a quienes portan las marcas diacríticas de negritud.

Negar la posibilidad de autorepresentarse a las personas alterizadas reside en que estas creaciones tienen el potencial de subvertir o promover la producción de fisuras en el sistema de dominación, siendo que las autorepresentaciones o contrarepresentaciones pueden poner en duda los supuestos en que se basan los estereotipos y construcciones reificadas sobre los "otros" y, por lo tanto, sobre el "nosotros" hegemónico. Al hablar de subversión retomo la idea de Dorlin (2009, p. 107) cuando -a través del análisis de las prácticas queer- establece que "[1]a línea de mira de toda política de subversión no consiste tanto en superar, destruir o abandonar dichos términos como en verdad más bien en impugnar, perturbar, transformar la relación que los engendra". Así, "[...] el concepto queer de subversión supone que no hay posición fuera del poder [...] sino más bien ejercicios múltiples de resistencia" (Dorlin, 2009 , p. 95). En este sentido, en la performance se hizo hincapié en varios elementos para enriquecer el subtexto de la representación y focalizar en la subversión de estereotipos o en la perturbación de discursos raciales/sexuales:

17 Sobre este tema, ver Geler (2011b). 
En primer lugar, la sola presencia de mujeres que se presentaban como afrodescendientes en el contexto de Buenos Aires sirvió para dar lugar a una primera "sorpresa" y al interés general del público que, en su mayoría, considera que los/las afrodescendientes son muy escasos/as y/o llegados/as en inmigraciones recientes. Entonces vino la segunda sorpresa, cuando algunas de las actrices dejaron escuchar su acento porteño, es decir, pudieron ser enmarcadas dentro de la connacionalidad o del ámbito cercano del Río de la Plata. La tercera sorpresa residió en que no todas estas mujeres podían ser consideradas socialmente negras. Por el contrario, muchas se ubicarían dentro de los márgenes de la mujer porteña "normal", desde la morocha hasta la rubia. De este modo, si como explica Hall (1997, p. 202, traducción mía) “el público que va a un museo espera que sus representaciones del mundo sean confirmadas o ampliadas, por el museo", en este caso ya desde el inicio de la situación el/la espectador/a vio sus propias representaciones subvertidas. Este tipo de intervenciones artísticas genera, a mi entender, la posibilidad de repreguntarse acerca de los propios orígenes y de la propia historia nacional, viabilizando la puesta en cuestión de mitos arraigados a la construcción estatal-nacional argentina, como el de su propia "blanquitud". En este sentido, se puede pensar, siguiendo a Dubatti (2007), en el teatro como una "zona de experiencia y subjetividad", que puede además alcanzar encarnadura vivencial en el público, potenciando así la capacidad desestabilizadora del proceso de subversión aumentada por el espacio museístico donde se desarrollaba la performance.

En segundo lugar, en el proceso de armado y ensayo de la performance se reflexionó con las actrices sobre la historia de Sara Baartman y se sopesaron las complejidades a que se enfrentaban al realizar una performance en el ámbito de un museo. Por un lado, es interesante destacar que, al ver sus imágenes por primera vez, algunas actrices sugirieron -en forma de broma- que así serían ellas en un futuro (en referencia a la esteatopigia, que se lee en Argentina como gordura). Ante la pregunta de por qué aseguraban esto, la respuesta común fue que sus madres, tías o abuelas eran así. ${ }^{18} \mathrm{El}$ reconocimiento inmediato de la figura de Baartman (sin conocer su historia) junto con la introyección de la imagen estereotípica -tan desconsoladamente

18 Charla grupal del 16 de octubre de 2010. 


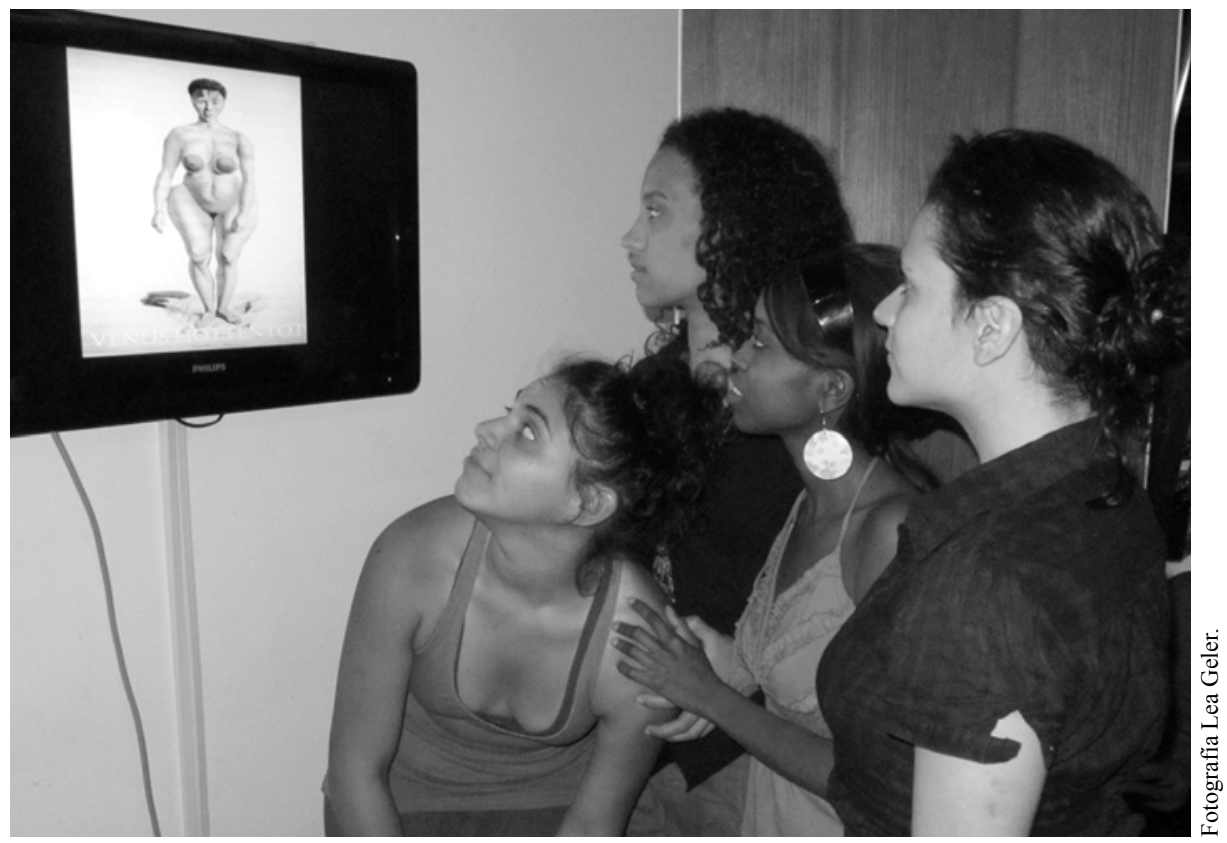

Figura 8. Ensayo de la performance en el Museo de la Mujer. Actrices interactuando con la imagen de Sara Baartman.

evocada por Fanon (1973) - y cómo ésta se proyectaba hacia el pasado pero también hacia el futuro, dejó en evidencia el peso del racismo y del sexismo en la vida cotidiana de las actrices. El desafío fue reutilizar estos sentidos en la interpretación, para transmitirlos al público en toda su densidad pero también para comenzar a fisurarlos. Así, había dos momentos específicos en la performance en que aparecía la imagen de Baartman proyectada, buscando generar intriga en un público que mayormente desconoce su historia pero, sobre todo, influyendo en la actuación y en el posicionamiento de las actrices para con el público y también entre sí: en la primera escena, dando comienzo a la performance, y en la última escena, marcando la salida del espacio escénico. En ambos momentos, después de unos minutos de estática (enseguida volveré sobre esto), las actrices se volteaban y miraban en conjunto la imagen proyectada por detrás de ellas, dando la espalda o el perfil al público que rodeaba la situación. Aquí era, entonces, la relación de 
las actrices con la imagen lo que fundamentaba el peso de la escena, y esa relación estuvo marcada por una memoria afectiva reencontrada o reconfigurada: el reconocimiento de una historia común, de un pasado que pervive pero que, mediante acciones artísticas-políticas como esta también encuentran vías de transformación, en un silencioso clamor que afectó de manera intensa (intelectual pero también corporalmente) a todas las involucradas en la performance. Y estos dos momentos conllevaron, en mi opinión, una inmensa energía interpretativa, siendo la tristeza, la fuerza y en algunos casos la rabia en la mirada de las actrices palpable también en el público y en el ambiente en general.

Por el otro, las actrices se sintieron directamente interpeladas por el caso de Baartman, el museo y la situación de ser objeto de una mirada continuamente sexualizada. De hecho, para algunas de ellas, aun siendo afrodescendientes socialmente blancas, la situación de estudiar o realizar bailes "afros" las posicionaba en esta mirada donde "lo negro es lo caliente, es lo tropical, es para coger". ${ }^{19}$ De este modo, la presencia del estereotipo de lo negro -como lo imaginado o fantaseado- sobrevuela a estas actrices y se experimenta continuadamente aun si sus cuerpos no portan el diacrítico diferenciador racial local. Y esta sensación se torna mucho más agresiva cuando el propio cuerpo se lee socialmente como negro, sucediéndole a una de las actrices que le preguntaran por la calle si sabía "bailar el caño", ${ }^{20}$ supuestamente para ofrecerle trabajo. En todo caso, hubo total acuerdo en que, tanto en Cuba, como en Colombia, Venezuela, Chile o Argentina, "el imaginario es el mismo", y que esto "viene de la esclavitud, de las violaciones... esto de decir que la mujer negra es tan sexual... es tan sexual que no me pude contener... y no es culpa mía, están para eso... Es un discurso hecho para eso". ${ }^{21}$

Esta situación de objetivación fue una de las más discutidas y tenidas en cuenta en la puesta en escena. Así, en tercer lugar, las actrices realizaron sus representaciones desde distintos lugares del espacio escénico pero interactuando con el mobiliario de la exposición general del museo que se podía recorrer a lo largo de la noche, especialmente con las esculturas de la artista uruguaya Mirta Olivera ubicadas en el hall central. Mientras sucedía la

\footnotetext{
19 Extracto de la charla de reflexión realizada el 16 de octubre de 2010.

${ }^{20}$ Idem.

21 Idem.
} 
performance, y paralelamente a la interpretación actoral, una de las actrices fue "armando" la muestra - es decir, se investía en curadora o guionista- a través del juego con las esculturas/objetos, ya que iba quitando unas mantas que las cubrían a la vez que dialogaba con ellas. Estas acciones organizaban el espacio, mientras las actrices eran ellas mismas espectadoras y también objeto de la mirada y de exhibición, ubicándolas en una condición de ambigüedad con respecto a su propia situación, reposicionándose continuamente en cada una de esas instancias y dejando en evidencia la tensión entre ser un objeto y ser un sujeto activo y con autoridad suficiente para realizar el montaje de una exhibición museística. La presentación de las actrices como objetos museísticos se hizo más específica al iniciar y, sobre todo, al terminar la obra, cuando éstas quedaron unos minutos formadas a la manera de fotografía antigua y en la pantalla (que exhibía durante la performance videos y fotografías) se mostraba simultáneamente la imagen de Baartman. Aunque en ese momento no podían moverse por el espacio escénico, las actrices sí continuaron interpretando, rompiendo una y otra vez con la estática del objeto y enfatizando la relación entre la mujer sudafricana de principios del siglo XIX y estas mujeres afrolatinoamericanas del siglo XXI en Buenos Aires. El teatro, según la apuesta de Egido, entraba al museo bajo la idea de es "un aire de sí pero no... El teatro es un hecho vivo e irrepetible". ${ }^{22}$ Así, que las actrices contaran con capacidad de respuesta y movimiento al tiempo que se quedaban como objetos de la muestra, "obliga a deshacer la colección, el objeto estático" ${ }^{23}$ o, por lo menos, a generar cierta confusión al respecto.

En cuarto lugar, Egido trabajó específicamente la corporalidad que debían asumir las actrices en escena, siendo que en ninguna ocasión se intentó un acercamiento a las representaciones estereotipadas de las mujeres socialmente negras para realizar una suerte de parodia -que podría llegar a tener un potencial crítico muy importante ${ }^{24}$ - sino que optó por lo contrario: situar los cuerpos dentro de las corrientes ideológicas hegemónicas que los envolvían. Es decir, si un texto pertenecía a la etapa del Romanticismo, el cuerpo de quien lo actuaba debía asumir una estética hegemónica de ese período, sin

\footnotetext{
22 Extracto de la charla de reflexión realizada el 16 de octubre de 2010.

${ }^{23}$ Charla informal con Alejandra Egido, agosto de 2010.

24 Ver los estudios de Judith Butler.
} 
importar si se era esclavizada, soldado o dama de la alta sociedad. Aunque aquí se corría el riesgo de mostrar una materialización del deseo de verse como el dominador (Bhabha, 2002; Fanon, 1973) -algo que, sin embargo, no dejaba de estar presente- el desajuste visual que se persiguió se relacionaba con producir un fuerte desplazamiento entre el texto, la imagen interpretativa y aquella que sería "esperable" según el estereotipo que asigna corporalidades específicas de acuerdo al posicionamiento de la persona en las coordenadas raza/sexo/clase social. En nuestro caso, lo "esperable" hubiera sido la presentación de movimientos sensuales o grotescos, por lo que se decidió asumir este peligro como primera instancia de crítica. Este desplazamiento quedaba a su vez realzado por el uso de la música - de estilo europeo, hegemónico- como forma de acompañamiento a las interpretaciones, que se quebraba solamente por la irrupción del sonido del tambor en el momento del candombe (sobre el que volveré enseguida). Del mismo modo, la vestimenta de todas las actrices fue moderna pero formal, completamente en color negro. Por un lado, Egido entendía que "la ropa negra es lo mejor. Sobriedad, lo que más presencia tenga sean los textos". ${ }^{25}$ Por el otro, nuevamente, la idea de desvincular la imagen resultante de lo que los textos estaban diciendo y del estereotipo que esos textos podían desprender volvía a poner de relieve el extrañamiento que se buscaba generar. Sin embargo, cada actriz tuvo un elemento de color rojo arreglado de modo distintivo. La razón a esto yacía en la idea de romper con que "todos los negros somos iguales". ${ }^{26}$

Es así que la interpretación del "Candombe de la negrada" -originalmente escrito para la obra teatral Calunga Andumba y que en aquella marcaba un momento de alegría y jolgorio, con baile incluido- aquí fue realizado sin movimiento ni alegría alguna y con el acompañamiento del tambor que agravaba la situación. Por el contrario, Egido pidió a las actrices que tomaran esta escena como un "grito de guerra", fulminando la típica imagen del "negro alegre" que sólo puede ser bueno para cantar y bailar, es decir, el "personaje del negro" que el teatro argentino ha sabido cultivar con creces.

${ }^{25}$ Charla grupal del 16 de octubre de 2010.

${ }^{26}$ Charla informal con Alejandra Egido, octubre de 2010. 


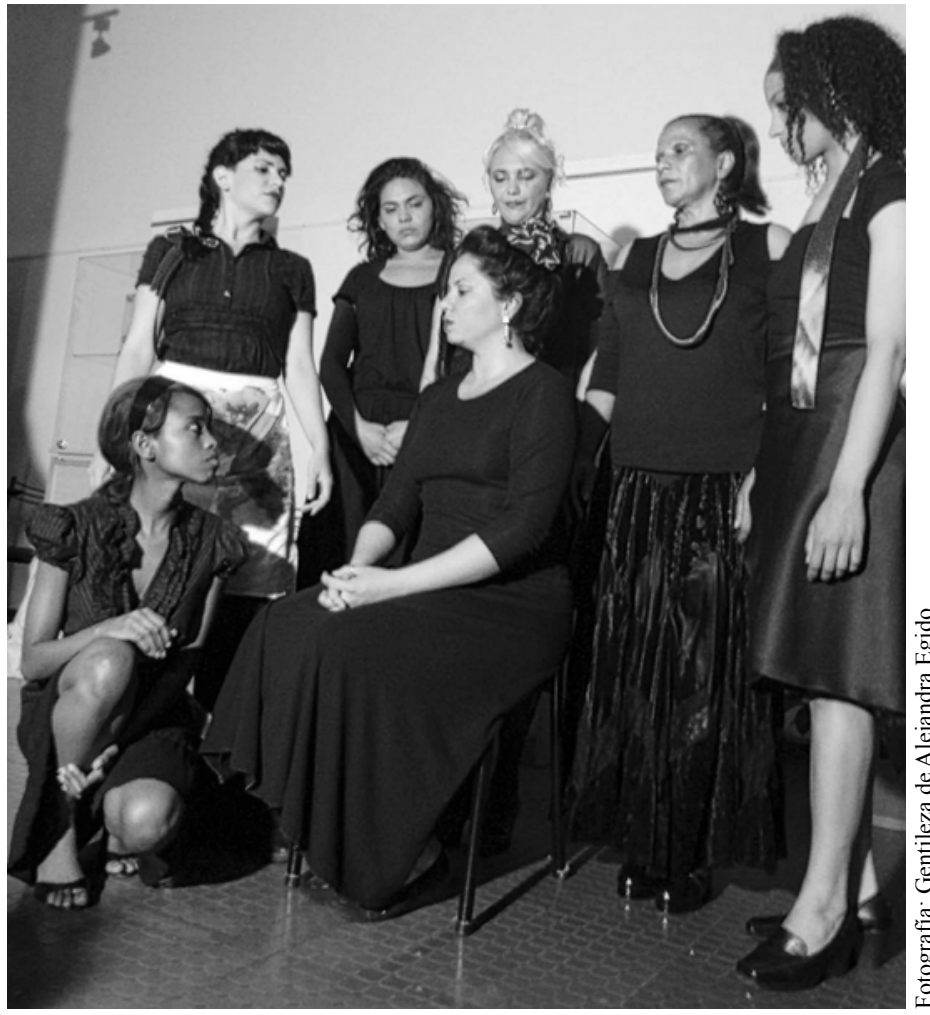

Figura 9. Momento de la performance en el Museo. Noviembre de 2010.

Por último, el proceso de creación y puesta de Afrolatinoamericanas... llevó a repensar también cómo se entroncan las experiencias de las mujeres en tanto grupo social subordinado, socialmente negras o blancas, permitiendo identificaciones en luchas más amplias:

Nos presentamos en un espacio feminista, que hasta entonces no manejaba que existíamos. Con lo cual, al contar nuestra historia, también va a haber guiños de «se parece mucho a la nuestra». Son historias de mujeres. Las violadas no somos sólo las negras, es todo el mundo. ${ }^{27}$

${ }^{27}$ Charla informal con Alejandra Egido, octubre de 2010. 
Así, el sólo hecho de poder presentarse en este espacio feminista que hasta el momento no había dado cuenta de la particularidad de las mujeres socialmente negras -como sucedió en muchas otras partes del mundo (hooks, 2004)- motivó que la misma institución cambiara varios de los supuestos con los que venía trabajando. El Museo de la Mujer, como espacio público subalterno de resistencia, abrió a su vez la posibilidad de crear nuevas subjetividades y nuevas alianzas de lucha, que sin embargo no deberán perder de vista la encarnadura vivencial de las diversas y múltiples formas de dominación con las que deben pelear las mujeres socialmente negras en el mundo.

Cabe destacar que a través de la reflexión, el ensayo, el trabajo grupal y utilizando el espacio museístico para potenciar el proceso de subversión, la performance generó un diálogo con el público para descentrarlo de sus supuestos cuyo el éxito fue notable. La cantidad de público que concurrió -que abarrotó las instalaciones y que dejó a mucha gente sin la posibilidad de ver ninguna de las dos funciones que se hicieron en la noche- y las preguntas con que buena parte del mismo salió del museo (muchas de las cuales fueron hechas a las actrices y a la directora después de la función) dieron cuenta de la situación. Pero, sobre todo, Afrolatinoamericanas... abrió un espacio hasta ese momento cerrado (e impensado) para generar autorepresentaciones que habiliten el diálogo con los supuestos y estereotipos asentados, esta vez sí, en más de 200 años de historia.

\section{Palabras finales}

Si la exposición de una mujer socialmente negra en Londres o en París en 1810 parecía no tener nada que ver con la Argentina de hoy, la performance Afrolatinoamericanas... desarrollada por el grupo teatral en el Museo de la Mujer de Buenos Aires abrió la posibilidad de demostrar cómo los sentidos que aquel suceso ponían en juego no sólo construyeron sino que continúan atravesando nuestro sentido común racializado. Y estos sentidos fueron encontrados, retomados y desestabilizados por las actrices y la directora -después de un profundo proceso de autorreflexión tanto intelectual como corporal- desde un espacio escénico muy particular: un espacio museístico, que en este caso era, además, un espacio de resistencia y de visibilización feminista. Justamente, al reutilizar la potencia de generar subjetividad del museo pero también del 
teatro, se abrió la posibilidad de fisurar esencialidades estereotipadas en una performance de autorepresentación que por su misma novedad ya era desestabilizadora, trastocando límites de los que tanto el museo anfitrión, como las creadoras y los/las espectadores/as debimos dar cuenta.

\section{Referencias}

ANDREWS, G. R. Los afroargentinos de Buenos Aires. Buenos Aires: De la Flor, 1989.

BHABHA, H. El lugar de la cultura. Buenos Aires: Manantial, 2002.

BRIONES, C. Formaciones de alteridad: contextos globales, procesos nacionales y provinciales. In: BRIONES, C. (Ed.). Cartografias argentinas: políticas indigenistas y formaciones provinciales de alteridad. Buenos Aires: Antropofagia, 2005. p. 11-43.

CONNERTON, P. How societies remember. Cambridge: Cambridge University Press, 1989.

CORRÊA, A. A los negros argentinos salud! Buenos Aires: Nuestra América, 2006.

DEBORD, G. La sociedad del espectáculo. Buenos Aires: Biblioteca de la Mirada, 1995.

DORLIN, E. Sexo, género y sexualidad: introducción a la teoría feminista. Buenos Aires: Nueva Visión, 2009.

DUBATTI, J. Cuerpo social y cuerpo poético en la escena argentina. E-misférica, n. 4.2, 2007. Disponible en: <http://hemi.nyu.edu/journal/4.2/ eng/en42_pg_dubatti.html $>$. Acceso en: 14 dic. 2010.

ECHEVERRÍA, E. El matadero: obras completas de D. Esteban Echeverría. Buenos Aires: Carlos Casavalle Editor, 1874. t. 5.

FANON, F. Piel negra, máscaras blancas. Buenos Aires: Abraxas, 1973. 
FERREIRA, L. Música, artes performáticas y el campo de las relaciones raciales. Área de estudios de la presencia africana en América Latina. In: LECHINI, G. (Comp.). Los estudios afroamericanos y africanos en América Latina. Córdoba: CEA-CLACSO, 2008. p. 225-250.

FRASER, N. Rethinking the public sphere: a contribution to the critique of actually existing democracy. In: CALHOUN, C. (Ed.). Habermas and the public sphere. Cambridge: The MIT Press, 1997. p. 109-142.

FRIGERIO, A. "Negros" y "blancos" en Buenos Aires: repensando nuestras categorías raciales. In: MARONESE, L. (Comp.). Buenos Aires negra: identidad y cultura. Buenos Aires: CPPHC, 2006. p. 77-98.

FRIGERIO, A. Luis D'Elia y los negros: identificaciones raciales y de clase en sectores populares. Claroscuro, Rosario, n. 8, p. 13-44, 2009.

GELER, L. La sociedad "de color" se pone de pie. Resistencia, visibilidad y esfera pública en la comunidad afrodescendiente de Buenos Aires, 1880. In: DALLA CORTE, G. et al. (Comp.). Homogeneidad, diferencia y exclusión en América Latina. Barcelona: PUB, 2006. p. 141-154.

GELER, L. "Nuestro sexo está de pie". Voces afrofemeninas en la Buenos Aires de 1876-78. Claroscuro, Rosario, n. 6, p. 109-137, 2007.

GELER, L. Andares negros, caminos blancos: afroporteños, Estado y Nación Argentina a fines del siglo XIX. Rosario: Prohistoria, 2010.

GELER, L. ¿Quién no ha sido negro en su vida? Performances de negritud en el carnaval porteño de fines del siglo XIX e inicios del XX. In: GARCÍA JORDÁN, P. (Coord.). El Estado en América Latina: control de los recursos, organización sociopolítica e imaginarios, siglos XIX-XXI. Barcelona: PUB, 2011a. p. 183-211.

GELER, L. Un personaje para la (blanca) nación argentina. El negro Benito, teatro y mundo urbano popular porteño a fines del siglo XIX. Boletín Americanista, Barcelona, n. 63, p. 77-99, 2011 b. 
GUZMÁN, F. Representaciones familiares de las mujeres negras en el Tucumán Colonial. Un análisis en torno al mundo doméstico subalterno. In: CELTON, D.; GHIRARDI, M.; CARBONETTI, A. (Comp.). Poblaciones históricas: fuentes, métodos y líneas de investigación. Rio de Janeiro: Asociación Latinoamericana de Población, 2009. p. 403-425. (Serie de Investigaciones, 9).

HALL, S. The spectacle of the "Other". In: HALL, S. (Ed.). Representation: cultural representations and signifying practices. London: Sage, 1997. p. 223290.

HALL, S. Nuevas etnicidades. In: RESTREPO, E.; WALSH, C.; VICH, V. (Ed.). Sin garantías: trayectorias y problemáticas en estudios culturales. Popayán: Envión/IEP/UASB, 2010. p. 305-313.

HOOKS, b. Mujeres negras: dar forma a la teoría feminista. In: OTRAS INAPROPIABLES: feminismos desde las fronteras. Madrid: Traficantes de Sueños, 2004. p. 33-50.

KROPFF, L. Construcciones de aboriginalidad, edad y politicidad entre jóvenes mapuche. Tesis (Doctorado en Antropología Social)-Universidad de Buenos Aires, Buenos Aires, 2008.

LIDCHI, H. The poetics and the politics of exhibiting other cultures. In: HALL, S. (Ed.). Representation: cultural representations and signifying practices. London: Sage, 1997. p. 151-222.

LUGONES, M. Colonialidad y género: hacia un feminismo descolonial. In: MIGNOLO, W. (Comp.). Género y descolonialidad. Buenos Aires: E. del Signo, 2008. p. 13-54.

MÁRMOL, J. Amalia. Leipzig: F. A. Brockhaus, 1872. t. 1.

PATTI, P. Una morena asoma en el teatro porteño. ¡Aqui está!, Buenos Aires, p. 8-9, 29 jul. 1946. 
PRECIADO, B. Beatriz Preciado entrevistada por Aimar Arriola. Pripublikarrak, 5 mayo 2008. Disponible en: <http://pripublikarrak.net/ blog/?p=425>. Acceso en: 15 sept. 2010.

QURESHI, S. Displaying Sara Baartman, the 'Hottentot Venus'. History of Science, Ceredigion, n. 42, p. 233-257, 2004.

RAMOS MEJÍA, J. M. Rosas y su tiempo. Buenos Aires: Félix Lajouane y Cía. Editores, 1907. t. 1.

RODRÍGUEZ, M. De la "extinción” a la autoafirmación: procesos de visibilización de la comunidad tehuelche Camusu Aike (provincia de Santa Cruz, Argentina). Tesis (Doctorado en Literatura y Estudios Culturales)Georgetown University, Washington DC, 2010.

TAULlARD, A. Nuestro antiguo Buenos Aires: cómo era y cómo es desde la época colonial hasta la actualidad. Su asombroso progreso edilicio, trajes, costumbres, etc. Buenos Aires: Peuser, 1927.

TROUILLOT, M.-R. Silencing the past: power and the production of history. Boston: Beacon Press, 1995. 